\title{
Using Stimulus-Equivalence Technology to Teach Skills About Nutritional Content
}

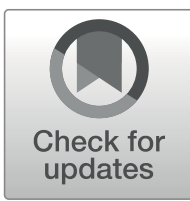

\author{
Erik Arntzen $^{1}$ iD $\cdot$ Jon Magnus Eilertsen ${ }^{1}$
}

Published online: 21 April 2020

(C) The Author(s) 2020

\begin{abstract}
Twenty-two adult participants, assigned to three conditions, were trained nutrition knowledge (i.e., carbohydrate values) for different food items. In a stimulus sorting test, the participants were asked to sort stimuli (names of food items) into one of three different ranges of carbohydrate values ("less than 20", "20-40", "more than 40" gram per 100 gram). Conditional-discrimination training and testing followed the sorting test, and finally, a postclass formation sorting test of the stimuli used in the conditionaldiscrimination training. The conditional-discrimination training used tailored stimuli, that is, the food items that each of the participants categorized incorrectly in the sorting test. Participants exposed to Conditions 1 and 2 were trained on six conditional discriminations and tested for the formation of three 3-member classes. Conditions 2 and 3 had a "don't know" option together with the three different ranges of carbohydrate values in the sorting for tailoring the stimuli. Participants exposed to Condition 3 trained were trained on 12 conditional discriminations and tested for the formation of three 5-member classes. The main findings showed that all but one of the participants responded correctly on at least one test for equivalence class formation and sorted the stimuli correctly in the postclass formation sorting test.
\end{abstract}

Keywords Carbohydrates $\cdot$ College students $\cdot$ Effectiveness $\cdot$ Nutrition $\cdot$ Stimulus equivalence

It is common to read information stating that food choice affects health, and that proper nutrition is related to a healthy lifestyle. Hence, to make these healthy food choices, nutritional knowledge is a prerequisite (Grunert et al., 2012). In particular, several authors have pointed out the importance of knowledge about nutrition as one of the factors for having good health (e.g., Lessa, Cortes, Frigola, \& Esteve, 2017; Miller \&

Erik Arntzen

erik.arntzen@equivalence.net

1 Department of Behavioral Science, Oslo Metropolitan University, PO Box 4, St. Olavs Plass, 0130 Oslo, Norway 
Cassady, 2015; Wardle, Parmenter, \& Waller, 2000). Furthermore, studies have shown a correlation between mother's knowledge about nutrition and healthy weights for their children (Yabancı, Kısaç, \& Karakuş, 2014), and less knowledge about nutrition was correlated with less compliance with the dietary guidelines for many food groups (Vereecken \& Maes, 2010).

A series of studies employing nutrition education have been shown to be effective in teaching knowledge about nutrition in adults (Allen, Smith Taylor, \& Kuiper, 2007; Clifford, Anderson, Auld, \& Champ, 2009; Tessaro, Rye, Parker, Mangone, \& McCrone, 2010) and in children (Pears et al., 2012). For example, Allen et al. (2007) found that a 30 -min session with information about nutrition influenced the choice of food in a simulated fast-food environment. Tessaro et al. (2010) used a computer-based interactive intervention (Cookin' Up Health) to teach women from a rural district knowledge about nutrition.

Nastally, Dixon, McKeel, and Fleming (2010) have argued that it is not clear what is the most efficient way to arrange procedures to increase knowledge about nutrition; strategies so far have included a variety of procedures, such as information about nutrition labels and food exposures. One such strategy that has been shown to be useful in teaching different skills in a variety of participants are procedures based on stimulusequivalence technology, known for more than 30 years. Later, the term "equivalencebased instruction" (EBI) has been used (Fienup, Covey, \& Critchfield, 2010). Examples of procedures based on stimulus-equivalence technology or EBI are summarized as follows: (1) establishing different skills in college students, such as (a) neuroanatomy (Fienup et al., 2010; Fienup, Mylan, Brodsky, \& Pytte, 2016; Pytte \& Fienup, 2012; Reyes-Giordano \& Fienup, 2015), (b) statistical inference (Critchfield \& Fienup, 2010; Fields et al., 2009; Fienup \& Critchfield, 2010, 2011; Fienup, Critchfield, \& Covey, 2009), (c) trigonometric relations (Ninness et al., 2009), and (d) intraverbals (Walker, Rehfeldt, \& Ninness, 2010); (2) establishing different skills in adults with brain injury (e.g., Cowley, Green, \& Braunling-McMorrow, 1992; Guercio, Podolska-Schroeder, \& Rehfeldt, 2004); (3) establishing different skills in typically developing children (Lynch \& Cuvo, 1995); (4) establishing different skills in people with autism spectrum disorder (ASD; e.g., Arntzen, Halstadtro, Bjerke, \& Halstadtro, 2010; Arntzen, Halstadtro, Bjerke, Wittner, \& Kristiansen, 2014; Stanley, Belisle, \& Dixon, 2018).

One line of research on healthy food choices has focused on how to influence participants' preferences. When studying food preference in children, procedures based on stimulus-equivalence technology have been used to investigate the formation of preference for brands of food and drinks (dos Santos \& de Rose, 2018, 2019) and the evaluation of food (Straatmann, Almeida, \& Rose, 2014). Additionally, procedures based on stimulus-equivalence technology have been used to make accurate portion size estimations among college students (Hausman, Borrero, Fisher, \& Kahng, 2014) and children (Hausman, Borrero, Fisher, \& Kahng, 2017).

Instead of manipulating food preferences, it is possible to teach participants the nutritional content of different food items. Nastally et al. (2010) exposed six college students to different tasks, including assessment of the caloric content of different food items. The participants were exposed to pre- and posttests for food preferences, preand posttests for the caloric content of different food items and to conditionaldiscrimination training with pictures of the food items from the second pretest. In the pretest for the caloric content, the participants were asked to sort pictures of 18 food 
items according to three categories of caloric content. These category cards were "Under 500 Calories," "500-1,000 Calories," and "Over 1,000 Calories." The participants were asked to name the food items and sort the items according to these categories. The stimuli mislabeled in the sorting test were used in the conditionaldiscrimination training. If there were not enough stimuli mislabeled, the experimenter selected a food item randomly. However, there was no information reported on how many times the experimenter had to pick a food item. Thus, whether any of the classes were partly formed before the conditional-discrimination training is not available to the reader. The conditional-discrimination training was arranged as two one-to-many (OTM) training structures. The first OTM training structure was performed with the category cards as A stimuli. The procedure started with training AB relations, followed by $\mathrm{AC}$ relations and a mix of $\mathrm{AB}$ and $\mathrm{AC}$ relations. The participants were then tested for the emergence of $\mathrm{BC}$ and $\mathrm{CB}$ relations in two 18-trial blocks. After a short break, the participants were exposed to a second OTM training with $\mathrm{CD}$ and $\mathrm{CE}$ relations arranged as the $\mathrm{AB}$ and $\mathrm{AC}$ training. This training was followed by testing for emergent relations of $\mathrm{BC}$ and $\mathrm{CB}$ relations in two 18-trial blocks, respectively. The results showed that training necessary conditional discriminations and testing emergent relations improved the nutrition labeling skills in all six participants. After the conditionaldiscrimination training, they found that participants were able to partition the stimuli according to the respective caloric content. Additionally, more than half of the participants made a healthier food choice after the training and testing.

Nastally et al. (2010) called for experiments with measurements of nutrition other than the caloric content of food items, such as carbohydrate levels of food items, which is also in accordance with the fact that several individuals are on a low-carb diet and may find that information more useful. Thus, it seems essential to determine whether conditional-discrimination training and testing for emergent relations with nutrition information about carbohydrates is as effective as shown in Nastally et al.

Most food items contain carbohydrates, such as fruits, grains and soft drinks, whereas others, such as different meat products and fish, do not (Norwegian Food Safety Authority, 2019). It is common knowledge that bread, pasta, beans, and potatoes are carbohydrate-rich foods, but not the precise quantity of carbohydrates per 100 gram found in these foods is not well known. For example, it is not apparent that raisins and pretzel sticks have more than $40 \mathrm{~g}$ of carbohydrates per $100 \mathrm{~g}$. Therefore, it could be useful to introduce a "don't know" option in a sorting test.

The overall goal of the present experiment was to employ procedures based on stimulus-equivalence technology to train knowledge about nutritional content (e.g., carbohydrate levels) in adult participants. To show the efficacy of an such a technology, it is essential to show how the approach is useful not only to small classes (names of food items) but also to larger classes (names of food items). Thus, the experiment includes three conditions in which participants were exposed to 6 or 12 conditional discriminations and were tested for the emergence of smaller classes (three 3-member classes) or larger classes (three 5-member classes). Additionally, we wanted to show the importance of tailoring stimuli for each participant. Therefore, the participants categorized the stimuli with name of different food items according to three levels of carbohydrate values ("less than 20", "20-40", "more than 40" gram per 100 gram) in a sorting test. The stimuli used in the conditional-discrimination training were stimuli that each participant did not categorize correctly according to the carbohydrate values. 
Finally, to explore whether the performance was maintained in a testing format other than matching-to-format (MTS), a postclass formation sorting test followed the conditional-discrimination training and testing.

\section{Method}

\section{Participants}

Twenty-two adults affiliated with Karlstad University and personal contacts participated in the experiment. Two more participants withdrew from the experiment, and their data were not included. The ages of the participants were between 19 and 54, with the mean age of 26 years. They were informed that the experiment was within the field of learning psychology. Participation in the experiment was compensated with 200 Swedish kroner (approximately US\$21.40). Each participant was quasi randomly assigned to one out of three conditions, with eight participants in Conditions 1 and 2, respectively, and six participants in Condition 3. The participants had to read a consent form upon arrival. The form stated who was conducting the experiment and that they would remain anonymous. Also, they were informed about their rights to withdraw from the experiment at any given time. Finally, the participants were fully debriefed at the end of the experiment.

\section{Apparatus and Setting}

The experiment was run in a quiet room at Karlstad University. The room was approximately $6 \mathrm{~m}^{2}$ and equipped with two chairs and a table. An HP ProBook 470 GP laptop computer running Windows 10 64-bit. The screen was 17.4 in. Participants used an external mouse to click on the stimuli. Custom-made software arranged and controlled the presentation of trials. The software recorded the order of the presented trials, the number of training and test trials, the reaction time to sample and comparison stimuli, correct/incorrect comparison choices, the delivery of programmed consequences, the duration of the experiment, and a summary of a participant's performance on an equivalence test.

\section{Stimuli}

Table 1 shows the stimuli used in the conditional-discrimination training and testing. The stimuli consisted of three ranges of carbohydrate values and the printed names of different food items. The food items were selected based on their carbohydrate content (Norwegian Food Safety Authority, 2019). The 21 stimuli in the top section of Table 1 were used for Conditions 1 and 2. All 33 stimuli were used for Condition 3. The carbohydrate range cards read "less than 20," "20-40," and "more than 40," except for two participants, P13500 and P13501, who had range cards that read " $0-20$," "20-40," and "40-80." Additionally, due to a procedural error, these two participants were shown 18 instead of 21 stimuli. In Conditions 2 and 3, a stimulus card with the text "don't know" was added to the three carbohydrate ranges. The size of the cards varied from $3 \mathrm{~cm} \times 3 \mathrm{~cm}$ to $5 \mathrm{~cm} \times 5 \mathrm{~cm}$. 
Table 1 Overview of the stimuli used in all three conditions

\begin{tabular}{lll}
\hline \multicolumn{1}{c}{1} & \multicolumn{1}{c}{2} & \multicolumn{1}{c}{3} \\
\hline Less than 20 & $20-40$ & More than 40 \\
Potatoes & Cashew nuts & Popcorn \\
Garlic, raw & Ketchup & Quinoa \\
Grapes & Tomato paste & Raisins \\
Bananas & Couscous & Garlic powder \\
Peanut butter & Dark chocolate $70 \%$ & White pepper \\
Carrots & Big One Classic & Axa fruit muesli \\
Raspberries & Boiled pasta & Oatmeal \\
Fish fingers & Taco spice mix & Taco shells \\
Blueberries & Boiled basmati rice & Polar bread \\
Brie & Frozen pommes frites & Crispbread, Wasa, Husman \\
Nestea Iced Tea & Pancakes & Pretzel sticks \\
\hline
\end{tabular}

Note. The 21 stimuli above the dashed line were employed for Conditions 1 and 2, respectively. All 33 stimuli were employed for Condition 3. The value for Quinoa is based for raw Quinoa

\section{Design and Dependent Measures}

The design is a demonstration of how participants learned carbohydrate levels when exposed to a procedure based on stimulus-equivalence technology. A sorting test is used to tailor the stimuli in the experiment. A postclass formation sorting test is used to study how the participants' class formation is maintained in a different test format. Dependent variables were the stimuli that were incorrectly grouped in the sorting test, trials to mastery criterion in the conditional-discrimination training, the percent correct responses during the test for emergent relations and the number of stimuli correctly grouped in the postclass formation test.

\section{Procedure}

Four different phases - sorting and tailoring of stimuli, conditional discrimination-training, and testing, and postclass formation sorting-were employed in the present experiment.

Phase 1: Sorting and Tailoring of Stimuli After signing the consent form, the participants were handed a deck of cards containing all of the printed food items. For participants in Conditions 1 and 2, the deck consisted of 21 printed food items, and in Condition 3, the deck consisted of 33 printed food items. The carbohydrate ranges were "less than 20," "20-40," and "more than 40."

The category names with carbohydrate ranges and the names of the different food items were presented on laminated plastic cards. The names were written in printed black text on a white background. Because we wanted the participants to group the food items according to the categories, the sorting was arranged as a table-top procedure. The stimulus cards with the labels of carbohydrate ranges were placed in front of 
the participants. The instructions to the participants were as follows: "On the table you will see 3 (4) category labels which indicate carbohydrate amounts per $100 \mathrm{~g}$ of each for the food items. Your task is to sort the food items into the categories you think they belong to." For Conditions 2 and 3, the participants were told that they could also sort the stimuli in the "don't know" category. The participants were told to let the experimenter know if they did not know the food item. The only food item some of the participants were uncertain about, was "Big One Classic." The experimenter told the participants that it was a frozen pizza. The experimenter left the room while the participants sorted the cards.

When the participants had sorted the cards, they were told to leave the room for a few minutes while the experimenter assessed the food items they had sorted incorrectly. The incorrectly sorted food items were used as stimuli in the conditional-discrimination training and testing. As a result, for each participant, the stimuli were individualized or tailored in training and testing. For participants in Conditions 1 and 2, two incorrectly sorted food items from each category were randomly chosen and used as stimuli B1 and C1, B2 and C2, B3, and C3. The categories "less than 20", "20-40", and "more than 40" were used as stimuli A1, A2, and A3, respectively. For the participants in Condition 3, six more incorrectly sorted food items were selected, D1, D2, D3, E1, E2, and E3. If in the Conditions 1 and 2, and Condition 3 participants did not make six or 12 incorrect sorting responses, respectively, the remaining stimuli were randomly chosen. Consequently, the experimenter had to choose one stimulus each for four participants. The stimuli were then loaded into the customized software and used during the conditionaldiscrimination training and testing and postclass formation sorting test.

Phase 2: Conditional-Discrimination Training The participants were seated in front of the computer, and the computer screen displayed the following written instructions:

Thank you for participating in the experiment. It is an experiment in learning psychology and requires no prior computer-knowledge. In short, you should click some stimuli that appear on the screen. The goal is to obtain as many correct choices as possible. When you move the mouse cursor onto the stimulus in the middle of the screen and click it, more stimuli will appear in the corners. Mouse clicks on one of the correct stimuli in the corners will be followed by presentation of the text "Correct" or similar. Clicking on one of the incorrect stimuli will be followed by the text "Wrong." This is how you will find out whether your response was correct and incorrect. After a while, you will not be notified if your response is correct or incorrect; no text will appear on the screen. Click start to begin the experiment.

When the participants clicked the start button, a stimulus appeared in the middle of the screen, and three other stimuli appeared in the corners of the screen. One corner remained blank, and the location of the blank corner was randomized. When the participant clicked one of the three stimuli in the corners, all stimuli disappeared, and programmed consequences were presented in the middle of the screen. If the participants clicked the stimulus defined as correct, words such as "Awesome," "Correct," and 
so on was presented. If they clicked the stimulus defined as incorrect, the word "Wrong" was presented. The programmed consequence was presented for $500 \mathrm{~ms}$ and was followed by an intertrial interval (ITI) of $500 \mathrm{~ms}$.

An OTM training structure was used to train the necessary conditional discriminations. The trials were presented on a concurrent basis, which means that for Conditions 1 and $2, \mathrm{AB}$ and $\mathrm{AC}$ trials were mixed from the beginning of the training, whereas in Condition 3, $\mathrm{AB}, \mathrm{AC}, \mathrm{AD}$, and $\mathrm{AE}$ trials were mixed from the beginning of the training. The baseline relations were presented in blocks of 30 trials for participants in Conditions 1 and 2 (see Table 2). For participants in Condition 3, the baseline relations were presented in blocks of 60 trials. A mastery criterion of $95 \%$ was required to proceed throughout the training blocks. The programmed consequences were presented for every trial until the participants met the mastery criterion in a block. Then, the programmed consequences were thinned in blocks from $75 \%$ to $50 \%$, and $0 \%$ as long as the participants met the mastery criterion in each block before the test phase for emergent relations. The number of training blocks required to reach the test varied across participants based on their performance.

Phase 3: Test for Emergent Relations The two test blocks consisted each of 54 trials for Conditions 1 and 2, and 180 trials for Condition 3. (See Table 2 for a detailed overview of the training and testing parameters, and the trained and tested relations.) The 54-trial block included 18 baseline ( $\mathrm{AB}$ and $\mathrm{AC}$ ), 18 symmetry (BA and $\mathrm{CA}$ ), and 18 equivalence $(\mathrm{BC}$ and $\mathrm{CB})$ trials. The criterion for responding in accordance with stimulus equivalence was a minimum of 17 of 18 correct trials $(94.4 \%)$. The 180 trial block included 36 baseline ( $\mathrm{AB}, \mathrm{AC}, \mathrm{AD}$, and $\mathrm{AE}), 36$ symmetry (BA, CA, DA, and $\mathrm{EA}$ ), and 108 equivalence (BC, CB, BD, DB, BE, EB, CE, EC, DE, and ED) trials. The criterion for responding in accordance with stimulus equivalence was a minimum of 34 of 36 baseline and symmetry trials and 102 of 108 equivalence trials (94.4\%). All

Table 2 Overview of parameters for trained and tested relations

\begin{tabular}{|c|c|c|c|}
\hline & Relations and trials per block & Mastery criterion & $\begin{array}{l}\text { Probability of } \\
\text { programmed } \\
\text { consequences }(\%)\end{array}$ \\
\hline \multicolumn{4}{|c|}{ Conditions 1 and 2} \\
\hline Training OTM & $30 \mathrm{AB}$ and $\mathrm{AC}$ trials & $96.7 \%$ & $100,75,50,0$ \\
\hline Testing & 54 Baseline, Symmetry, and Equivalence trials & $\begin{array}{l}\text { Min of } 94.4 \% \text { correct } \\
\text { of each relation type }\end{array}$ & 0 \\
\hline & $\mathrm{AB}, \mathrm{AC}, \mathrm{BA}, \mathrm{CA}, \mathrm{CB}, \mathrm{BC}$ & & \\
\hline \multicolumn{4}{|l|}{ Condition 3} \\
\hline Training OTM & $\mathrm{AB}, \mathrm{AC}, \mathrm{AD}, \mathrm{AE}$ & $95 \%$ & $100,75,50,0$ \\
\hline Testing & $\begin{array}{l}180 \text { Baseline, Symmetry, and Equivalence trials } \\
\mathrm{AB}, \mathrm{AC}, \mathrm{AD}, \mathrm{AE}, \mathrm{BA}, \mathrm{CA}, \mathrm{DA}, \mathrm{EA}, \mathrm{BC} \\
\mathrm{BC}, \mathrm{BD}, \mathrm{BE}, \mathrm{CB}, \mathrm{CD}, \mathrm{CE}, \mathrm{DB}, \mathrm{DC}, \mathrm{DE} \\
\mathrm{EB}, \mathrm{EC}, \mathrm{ED}\end{array}$ & $\begin{array}{l}\text { Min of } 94.4 \% \text { correct } \\
\text { of each relation type }\end{array}$ & 0 \\
\hline
\end{tabular}


trials in the test blocks were presented under extinction conditions with no programmed consequences.

Phase 4: Postclass Formation Sorting When the participants had completed the test for emergent relations, the written text "congratulations, you can now contact the experimenter" appeared on the screen. The participants were asked to briefly leave the room while the experimenter (the second author) arranged the postclass formation sorting. The sorting test was done with customized software (and not arranged as a table-top test as in the sorting test) on the same laptop computer that administered the conditionaldiscrimination training and testing. The participants were seated in front of the computer, and the computer screen displayed the following written instructions:

Sort the pictures as you want. When you have sorted the pictures as you want, please mark the sorting by holding down the left mouse button and draw by moving the mouse. The stimuli will be placed on top of each other; you will have to drag them to any other location on the screen. By moving one of the stimuli, you can undo the drawn markings.

All of the stimuli used during the conditional-discrimination training and testing were presented on top of each other in a stack. The order of the stimuli in the stack was randomized across presentations. The participants were told that the sorting test would be presented twice, and then the experiment was finished.

\section{Interobserver Agreement}

The experimenter and another trained person scored whether the stimuli used in the conditional-discrimination training and testing for emergent relations were the stimuli that the participants did not categorize correctly in the sorting test. Thirty percent of all cases were scored. The interobserver agreement was scored as agreement/total number of cases $\times 100$ (Kazdin, 1982) and was found to be $96.6 \%$.

\section{Results}

\section{Sorting and Tailoring of Stimuli}

Figure 1 shows the number of times each of the food items were incorrectly sorted for Conditions 1, 2, and 3, respectively. For all groups, a large number of items were categorized incorrectly. Figure 2 shows the details about the top five food items that were incorrectly sorted. Bananas were incorrectly sorted as "20-40" and "more than 40" carbohydrates per $100 \mathrm{~g}$. Peanut butter was mainly sorted incorrectly as "more than 40" carbohydrates per $100 \mathrm{~g}$. Potatoes were incorrectly sorted as "20-40" and "more than 40" carbohydrates per $100 \mathrm{~g}$. White pepper was mainly sorted incorrectly as "less than 20" carbohydrates per 100 g. Garlic powder was 

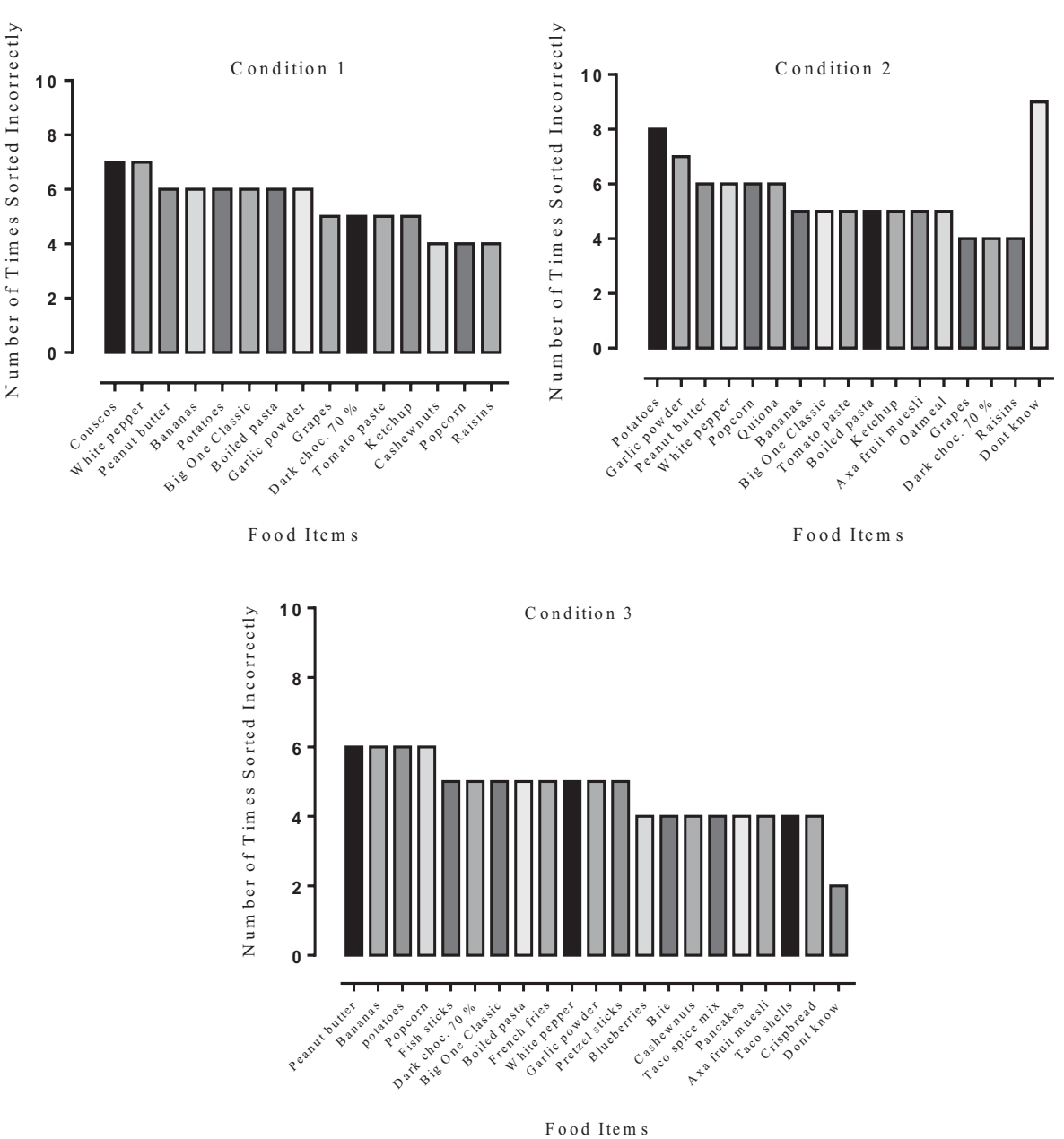

Fig. 1 Total number of times the different food items were sorted incorrectly for Conditions 1, 2, and 3. Food items sorted incorrectly fewer than four times are not included in the figure

sorted incorrectly as "less than 20" and "20-40" carbohydrates per $100 \mathrm{~g}$ but also as the "don't know" option. The number of times the different food items were used in the conditional-discrimination training is shown in Figure 3.

Four participants, P13501, P13503, P13506, and P13512 were provided with an MTS task containing one food item previously sorted correctly. The remaining participants made enough incorrect sorting responses during the sorting test, so we could use 6 or 12 stimuli incorrectly sorted stimuli for participants in Conditions 1 and 2 and participants in Condition 3, respectively.

\section{Duration of the Experimental Sessions}

Conditional-discrimination training and testing lasted from 15 to $24 \mathrm{~min}$ for the participants in the first two groups. For participants in the third group, the training and testing lasted from 45 to $84 \mathrm{~min}$. 


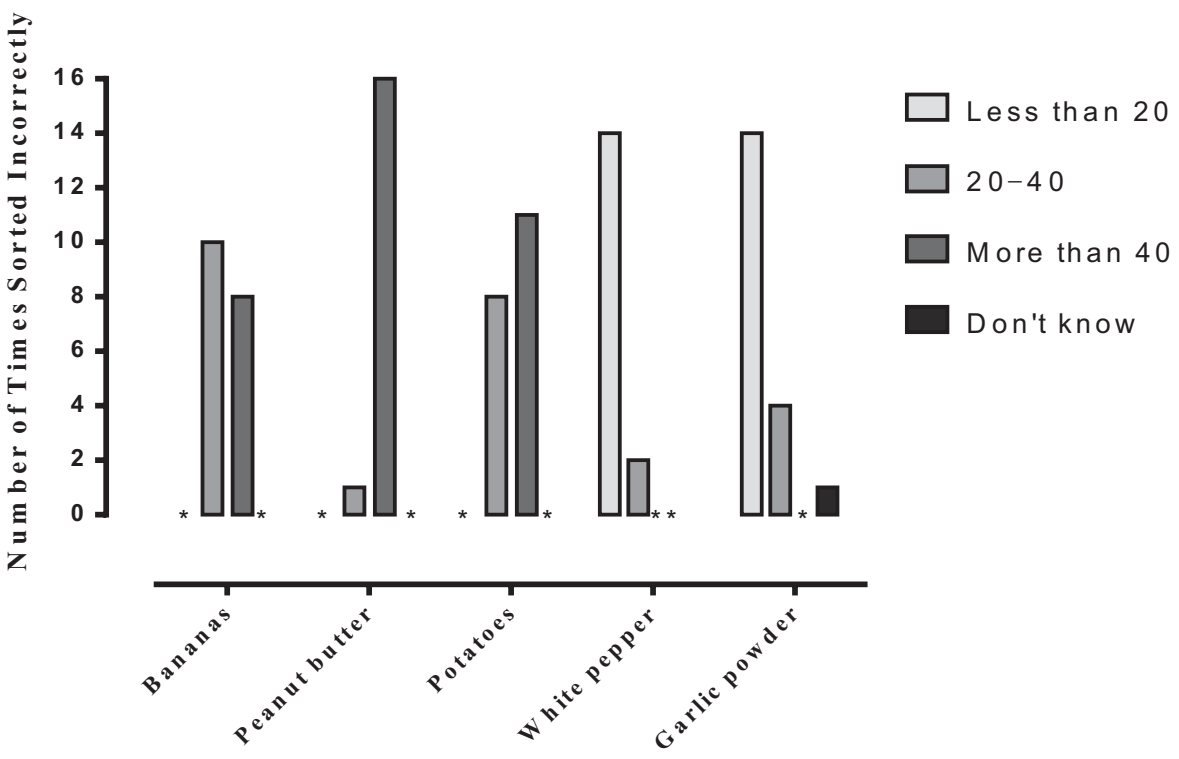

Food Items

Fig. 2 Five food items were ranked as the top three incorrectly sorted items. Notes. $*=$ no participant sorted the item at that specific carbohydrate range

\section{Training Trials}

For participants in Condition 1, the mean trials to the mastery criterion was 169 (150240) (see Table 3). Participants in Condition 2 had a mean of 165 trials (150-240), and in Condition 3, the mean was 400 (240-640).

\section{Equivalence Class formation}

All of the participants were exposed to two tests for emergent relations. Six out of the eight participants in Condition 1 responded in accordance with equivalence, and the remaining two participants responded in accordance with equivalence in the second test (see Table 3). All participants in Condition 2 responded in accordance with stimulus equivalence in both of the tests. In Condition 3, five of six participants responded in accordance with equivalence in both tests.

\section{Postclass Formation Sorting Tests}

In the postclass formation sorting test, all the participants in Conditions 1 and 2 sorted the stimuli in accordance with the experimenter-defined classes (see Table 3). The one participant (P13518) who did not respond in accordance with equivalence did not sort the stimuli correctly in the sorting test. The participant sorted only two of the 12 stimuli correctly in both sorting tests. During the debriefing, the participant said that she knew 


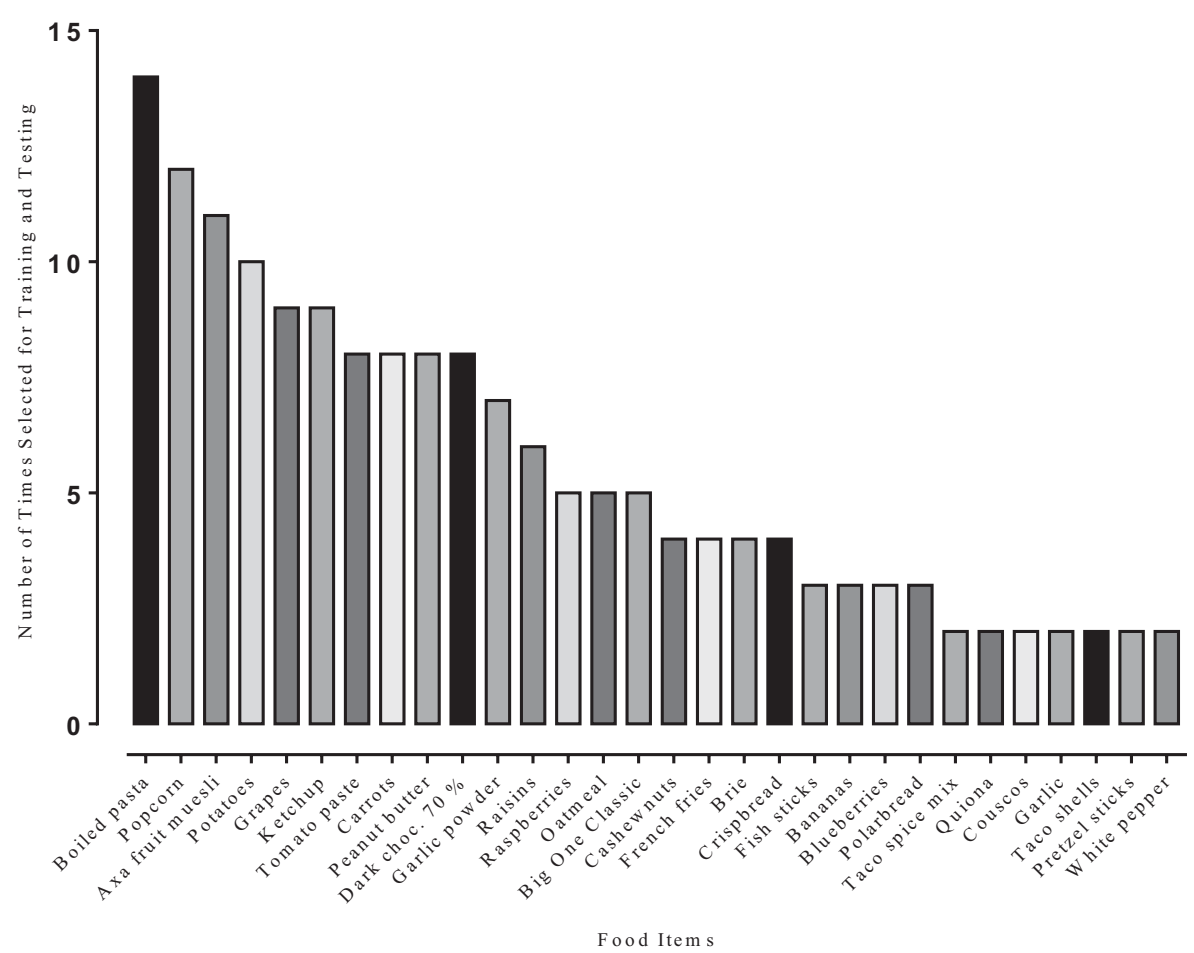

Fig. 3 Number of times different stimuli were used during training of conditional discriminations and testing for emergent relations

the experimenter-defined classes, but she chose to respond in accordance with the classes she had sorted during the initial sorting task in the test for emergent relations.

Table 3 Overview of the results

\begin{tabular}{|c|c|c|c|c|c|c|c|c|c|c|c|}
\hline \multicolumn{4}{|c|}{ Condition 1} & \multicolumn{4}{|c|}{ Condition 2} & \multicolumn{4}{|c|}{ Condition 3} \\
\hline P\# & Trials & EQ & Post & P\# & Trials & EQ & Post & P\# & Trials & EQ & Post \\
\hline 13500 & 150 & $\mathrm{y} / \mathrm{y}$ & $6 / 6$ & 13510 & 240 & $\mathrm{y} / \mathrm{y}$ & $6 / 6$ & 13516 & 360 & $y / y$ & $12 / 12$ \\
\hline 13501 & 180 & $\mathrm{y} / \mathrm{y}$ & $6 / 6$ & 13511 & 150 & $\mathrm{y} / \mathrm{y}$ & $6 / 6$ & 13519 & 660 & $\mathrm{y} / \mathrm{y}$ & $12 / 12$ \\
\hline 13502 & 180 & $\mathrm{y} / \mathrm{y}$ & $6 / 6$ & 13512 & 120 & $\mathrm{y} / \mathrm{y}$ & $6 / 6$ & 13521 & 360 & $\mathrm{y} / \mathrm{y}$ & $12 / 12$ \\
\hline 13503 & 180 & $\mathrm{y} / \mathrm{y}$ & $6 / 6$ & 13513 & 180 & $\mathrm{y} / \mathrm{y}$ & $6 / 6$ & 13522 & 420 & $\mathrm{y} / \mathrm{y}$ & $12 / 12$ \\
\hline 13505 & 150 & $\mathrm{y} / \mathrm{y}$ & $6 / 6$ & 13514 & 150 & $\mathrm{y} / \mathrm{y}$ & $6 / 6$ & 13525 & 420 & $\mathrm{y} / \mathrm{y}$ & $12 / 12$ \\
\hline 13507 & 150 & $y / y$ & $6 / 6$ & 13515 & 150 & $\mathrm{y} / \mathrm{y}$ & $6 / 6$ & 13518 & 469 & $\mathrm{n} / \mathrm{n}$ & $2 / 2$ \\
\hline 13504 & 180 & $\mathrm{n} / \mathrm{y}$ & $6 / 6$ & 13523 & 150 & $\mathrm{y} / \mathrm{y}$ & $6 / 6$ & & & & \\
\hline 13506 & 180 & $\mathrm{n} / \mathrm{y}$ & $6 / 6$ & 13524 & 180 & $\mathrm{y} / \mathrm{y}$ & $6 / 6$ & & & & \\
\hline
\end{tabular}

Note. Column P\# shows the participant number. Column EQ shows responding in accordance with stimulus equivalence (y) or not (no) in the two test blocks. Column Post shows the number of correct stimuli sorted in the two sorting, postclass formation tests 


\section{Discussion}

\section{General Comments}

In Phase 1, sorting and tailoring of stimuli, we included the "don't know" option in Conditions 2 and 3 because the knowledge of the carbohydrates level was in general low for participants in Condition 1. The inclusion of the "don't know" option was inspired by experiments that have included an additional option for giving a nonclassbased response in the test for emergent relations (e.g., Imam \& Blanche, 2013). In the present experiment, the result of including "don't know" showed that it was selected more in Condition 2 than in Condition 3, even if the number of stimuli in the sorting test was higher in Condition 3 than in Condition 1 . The difference was mainly related to the performance of two participants in Condition 3 who used the "don't know" option for several food items.

After the procedure based on stimulus-equivalence technology, 21 out of 22 participants responded in accordance with stimulus equivalence and sorted the stimuli according to the experimenter-defined classes. The greater number of training trials is the result of training on 12 conditional discriminations in Condition 3, while 6 conditional discriminations were trained in Conditions 1 and 2.

The goal of the present experiment was not to compare different methods for promoting knowledge about nutrition but rather to show how procedures based on stimulus-equivalence technology can be used to foster learning abilities within a specific context (e.g., de Abreu César \& Moroz, 2018; Walker \& Rehfeldt, 2012). The reason for using such technology is based on a substantial amount of research showing that training a few relations, will produce a larger number of relations that are not directly trained. Additionally, we wanted to show the effect of emergent relations not only after training a small number of conditional discriminations (Conditions 1 and 2) but also by including a greater number of conditional discriminations (Condition 3). Early in the history of research on stimulus equivalence, Sidman, Kirk, and WillsonMorris (1985) showed that it was possible by training 15 conditional relations to produce 60 emergent relations. Thus, the emergence of several untrained relations is in accordance with other experiments using procedures based on stimulus-equivalence technology or EBI (e.g., Fienup et al., 2016).

A necessary next step is the implementation of the laboratory procedure described in the present experiment in a classroom setting (see, e.g., Fienup et al., 2016) and a comparison of the effects of the procedure with traditional ways of teaching categories. Some studies have compared the effect of EBI and procedures based on other types of instructions, such as unstructured flash-card practice and have shown the superiority of the former (Zinn, Newland, \& Ritchie, 2015).

Two of the participants in Condition 1 showed an increase in responding in accordance with experimenter-defined classes. Such an increase in responding according with equivalence class formation could be described as delayed emergence of equivalence. Such type of response pattern is reported in other experiments (e.g., Arntzen \& Mensah, 2020; Arntzen \& Nartey, 2018) and emphasizes the importance of having at least two test blocks to be able to observe changes during testing. 


\section{Tailoring of Stimuli}

In basic research on stimulus equivalence, experiments are arranged with conditional discriminations of abstract shapes that are arbitrarily related, and due to the training of conditional discriminations and testing of emergent relations the stimuli in the set are partitioned into different classes (e.g., Sidman \& Tailby, 1982). However, in experiments characterized as stimulus-equivalence technology or EBI, the stimuli used are often meaningful stimuli and definitely not abstract shapes (e.g., Fienup et al., 2010; Varelas \& Fields, 2017), and it could be that some of the stimuli are already part of the trained stimulus classes. Thus, individually tailoring the stimuli, as was done in the present experiment, is essential. Hence, the stimuli used for each participant were tailored based on the results from the sorting test. This type of arrangement for tailoring of the stimuli used in the present experiment is in accordance with other experiments (Nastally et al., 2010), and tailored nutritional education has been highlighted by other researchers (Oenema, Brug, \& Lechner, 2001).

\section{Correspondence of Test Formats}

The findings in the present experiment showed a high correspondence between equivalence-class formation in the MTS test and sorting according to experimenter-defined classes. These results are in accordance with a series of experiments (e.g., Arntzen, Granmo, \& Fields, 2017). Sorting is an alternative measurement, especially in applied settings, because it is less time-consuming than the MTS test and easy to administer (e.g., Rustad Bevolden \& Arntzen, 2018) and can also be useful in studies involving procedures based on stimulus-equivalence technology or EBI.

\section{Limitations and Further Experiments}

The design in the present study is only a demonstration and future research should use either a between-subjects or within-subject design. For four of the participants, one of the stimuli employed in the conditional-discrimination training was a correctly sorted food item. For P13512, who had been trained on 12 conditional discriminations, this was not as influential for the three other participants (P13501, P13503, and P13506), who had been trained on six conditional discriminations. It is important to note that the results of these four participants did not differ from the other participants with respect to performance on the MTS tests. Additionally, three of the participants, P13501, P13503, and P13506, had more trials to mastery criterion than the average for the group, whereas P131512 had a fewer trials than the average. On the other hand, Nastally et al. (2010) do not report how many stimuli or how many participants performed the MTS tasks with stimuli they had sorted correctly during Phase 1.

The carbohydrate values differ for some of the food items depending on if they are raw or cooked. It is important to emphasize that even if this information was not given for all food items it did not influence the results in establishing the conditional discriminations. However, in further research, this should be specified in more detail. 
Nastally et al. (2010) included some participants with a high BMI, which was not part of the aim in the present experiment. However, there is a need for relating knowledge about nutrition regarding carbohydrates, as in the present experiments with an arrangement of diets to reduce weight or for type 2 diabetes management as emphasized in other types of research (e.g., Foster, 2006; Tay et al., 2015).

In further experiments, the postclass formation sorting test should be arranged before the MTS test to explore the correspondence between the two test formats (see, e.g., Arntzen et al., 2017). If the sorting test after training shows partitioning of classes, such tests could be beneficial in applied settings. Additionally, future studies should include follow-up tests for evaluating the long-term effects of MTS training.

\section{Summary and Implications}

The present experiment replicated the findings from Nastally et al. (2010). It showed the effectiveness of using a tailored selection of stimuli used in a computerized procedure to produce classes of stimuli of food items within the same range of carbohydrate values that were not explicitly trained. We would argue that tailoring stimuli should be an essential feature of EBI research.

There are several implications of this type of stimulus-equivalence technology study, regarding efficiency and efficacy. First, the duration of the experimental sessions shows that the procedure is not time consuming but is still effective in training knowledge about carbohydrate values for different food items. The difference in duration between Conditions 1 and 2, in comparison to Condition 3, is related to the number of conditional discriminations trained and tested. Second, the procedure based on stimulus-equivalence technology efficiently improved knowledge about the nutritional content in a variety of food items.

It is important to distinguish between slow and fast carbohydrates. A variety of fruits and vegetables, as well as grains such as whole wheat, are examples of slow carbohydrates. Fast carbohydrates are, for example, found in drinks and refined grains such as white rice and those in cornbread, white bread, grits, and couscous. Characteristically, fast carbohydrates will be low in fiber, whereas slow carbohydrates are fiber-rich and healthy nutrients. Blood sugar rises faster after consumption of fast carbohydrates compared to slow carbohydrates, and the differences in blood sugar level will influence how soon you will feel hungry after having eaten (e.g., Chandler-Laney et al., 2014). Increasing the intake of slow carbohydrates while minimizing or eliminating fast carbohydrates is key to improving health; thus, it is essential to teach participants in stimulus-equivalence technology research projects to differentiate between slow and fast types of carbohydrates.

Funding Information Open Access funding provided by OsloMet - Oslo Metropolitan University. This research was funded by Oslo Metropolitan University.

\section{Compliance with Ethical Standards}

Conflict of Interest The authors declare that there is no conflict of interest. 
Ethical Approval All procedures performed in studies involving human participants were in accordance with the ethical standards and with the 1964 Helsinki Declaration and its later amendments or comparable ethical standards.

Informed Consent Informed consent was obtained from all individual participants included in the study.

Open Access This article is licensed under a Creative Commons Attribution 4.0 International License, which permits use, sharing, adaptation, distribution and reproduction in any medium or format, as long as you give appropriate credit to the original author(s) and the source, provide a link to the Creative Commons licence, and indicate if changes were made. The images or other third party material in this article are included in the article's Creative Commons licence, unless indicated otherwise in a credit line to the material. If material is not included in the article's Creative Commons licence and your intended use is not permitted by statutory regulation or exceeds the permitted use, you will need to obtain permission directly from the copyright holder. To view a copy of this licence, visit http://creativecommons.org/licenses/by/4.0/.

\section{References}

Allen, K. N., Smith Taylor, J., \& Kuiper, R. (2007). Effectiveness of nutrition education on fast food choices in adolescents. The Journal of School Nursing, 23, 337-341.

Arntzen, E., Granmo, S., \& Fields, L. (2017). The relation between sorting tests and matching-to-sample tests in the formation of equivalence classes. Psychological Record, 67, 81-96. https://doi.org/10.1007 /s40732-016-0209-9.

Arntzen, E., Halstadtro, L. B., Bjerke, E., \& Halstadtro, M. (2010). Training and testing theoretical music skills in a boy with autism using a matching-to-sample format. Behavioral Interventions, 25, 129-143. https://doi.org/10.1002/bin.301.

Arntzen, E., Halstadtro, L. B., Bjerke, E., Wittner, K. J., \& Kristiansen, A. (2014). On the sequential and concurrent presentation of trials establishing prerequisites for emergent relations. Behavior Analyst Today, 14, 23-30. https://doi.org/10.1037/h0101280.

Arntzen, E., \& Nartey, R. K. (2018). Equivalence class formation as a function of preliminary training with pictorial stimuli. Journal of the Experimental Analysis of Behavior, 110, 275-291. https://doi.org/10.1002 jeab.466.

Arntzen, E., \& Mensah, J. (2020). On the effectiveness of including meaningful pictures in the formation of equivalence classes. Journal of the Experimental Analysis of Behavior. https://doi.org/10.1002/jeab.579.

Chandler-Laney, P. C., Morrison, S. A., Goree, L. L., Ellis, A. C., Casazza, K., Desmond, R., et al. (2014). Return of hunger following a relatively high carbohydrate breakfast is associated with earlier recorded glucose peak and nadir. Appetite, 80, 236-241. https://doi.org/10.1016/j.appet.2014.04.031.

Clifford, D., Anderson, J., Auld, G., \& Champ, J. (2009). Good grubbin': impact of a TV cooking show for college students living off campus. Journal of Nutrition Education and Behavior, 41, 194-200. https://doi. org/10.1016/j.jneb.2008.01.006.

Cowley, B. J., Green, G., \& Braunling-McMorrow, D. (1992). Using stimulus equivalence procedures to teach name-face matching to adults with brain injuries. Journal of Applied Behavior Analysis, 25, 461-475. https://doi.org/10.1901/jaba.1992.25-461.

Critchfield, T. S., \& Fienup, D. M. (2010). Using stimulus equivalence technology to teach statistical inference in a group setting. Journal of Applied Behavior Analysis, 43, 763-768. https://doi.org/10.1901 jaba.2010.43-763.

de Abreu César, M., \& Moroz, M. (2018). Teaching chemistry based on the stimulus equivalence model. Paidéia (Ribeirão Preto), 28. https://doi.org/10.1590/1982-4327e2838

dos Santos, S. L., \& de Rose, J. C. (2018). Investigating the impact of stimulus equivalence on children's food choice and preference. Temas em Psicologia, 26, 1-14. https://doi.org/10.9788/tp2018.1-01.

dos Santos, S. L., \& de Rose, J. C. (2019). Influence of cartoon characters on children's food preference via transfer of functions. The Psychological Record, 69, 153-163. https://doi.org/10.1007/s40732-018-03277

Fields, L., Travis, R., Roy, D., Yadlovker, E., de Auguiar-Rocha, L., \& Sturmey, P. (2009). Equivalence formation: a method for teaching statistical interaction. Journal of Applied Behavior Analysis, 42, 575593. https://doi.org/10.1901/jaba.2009.42-575. 
Fienup, D. M., Covey, D. P., \& Critchfield, T. S. (2010). Teaching brain-behavior relations economically with stimulus equivalence technology. Journal of Applied Behavior Analysis, 43, 19-33. https://doi. org/10.1901/jaba.2010.43-19.

Fienup, D. M., \& Critchfield, T. S. (2010). Efficiently establishing concepts of inferential statistics and hypothesis decision making through contextually controlled equivalence classes. Journal of Applied Behavior Analysis, 43, 437-462. https://doi.org/10.1901/jaba.2010.43-437.

Fienup, D. M., \& Critchfield, T. S. (2011). Transportability of equivalence-based programmed instruction: efficacy and efficiency in a college classroom. Journal of Applied Behavior Analysis, 44, 435-450. https://doi.org/10.1901/jaba.2011.44-435.

Fienup, D. M., Critchfield, T. S., \& Covey, D. P. (2009). Building contextually-controlled equivalence classes to teach about inferential statistics: a preliminary demonstration. Experimental Analysis of Human Behavior Bulletin, 27, 1-10.

Fienup, D. M., Mylan, S. E., Brodsky, J., \& Pytte, C. (2016). From the laboratory to the classroom: the effects of equivalence-based instruction on neuroanatomy competencies. Journal of Behavioral Education, 25, 143-165. https://doi.org/10.1007/s10864-015-9241-0.

Foster, G. D. (2006). Clinical implications for the treatment of obesity. Obesity, 14, S182-S185. https://doi. org/10.1038/oby.2006.303.

Grunert, K. G., Wills, J., Fernandez-Celemín, L., Lähteenmäki, L., Scholderer, J., \& Storcksdieck genannt Bonsmann, S. (2012). Socio-demographic and attitudinal determinants of nutrition knowledge of food shoppers in six European countries. Food Quality and Preference, 26, 166-177. https://doi.org/10.1016/j. foodqual.2012.04.007.

Guercio, J. M., Podolska-Schroeder, H., \& Rehfeldt, R. A. (2004). Using stimulus equivalence technology to teach emotion recognition to adults with acquired brain injury. Brain Injury, 18, 593-601 Retrieved from ISI:000220753700006.

Hausman, N. L., Borrero, J. C., Fisher, A., \& Kahng, S. (2014). Improving accuracy of portion-size estimations through a stimulus equivalence paradigm. Journal of Applied Behavior Analysis, 47, 485499. https://doi.org/10.1002/jaba.139.

Hausman, N. L., Borrero, J. C., Fisher, A., \& Kahng, S. (2017). Teaching young children to make accurate portion size estimations using a stimulus equivalence paradigm. Behavioral Interventions, 32, 121-132. https://doi.org/10.1002/bin.1466.

Imam, A. A., \& Blanche, J. V. (2013). Effects of a CARO on stimulus equivalence formation: a systematic replication. Psychological Record, 63, 141-156. https://doi.org/10.11133/j.tpr.2013.63.1.011.

Kazdin, A. E. (1982). Single-case research designs. New York, NY: Oxford University Press.

Lessa, K., Cortes, C., Frigola, A., \& Esteve, M. J. (2017). Food healthy knowledge, attitudes and practices: survey of the general public and food handlers. International Journal of Gastronomy \& Food Science, 7 , 1-4. https://doi.org/10.1016/j.ijgfs.2016.11.004.

Lynch, D. C., \& Cuvo, A. J. (1995). Stimulus equivalence instructions of fraction-decimal relations. Journal of Applied Behavior Analysis, 28, 115-126. https://doi.org/10.1901/jaba.1995.28-115.

Miller, L. M. S., \& Cassady, D. L. (2015). The effects of nutrition knowledge on food label use. A review of the literature. Appetite, 92, 207-216. https://doi.org/10.1016/j.appet.2015.05.029.

Nastally, B., Dixon, M. R., McKeel, A., \& Fleming, M. (2010). Teaching healthy food choices through stimulus equivalence. Journal of Behavioral Health \& Medicine, 1, 119-126.

Ninness, C., Dixon, M., Barnes-Holmes, D., Rehfeldt, R. A., Rumph, R., McCuller, G., et al. (2009). Constructing and deriving reciprocal trigonometric relations: a functional analytic approach. Journal of Applied Behavior Analysis, 42, 191-208. https://doi.org/10.1901/jaba.2009.42-191.

Norwegian Food Safety Authority. (2019, April 30). Norwegian Food Composition Database. Retrieved from www.matvaretabellen.no

Oenema, A., Brug, J., \& Lechner, L. (2001). Web-based tailored nutrition education: results of a randomized controlled trial. Health Education Research, 16, 647-660.

Pears, S. L., Jackson, M. C., Bertenshaw, E. J., Horne, P. J., Fergus Lowe, C., \& Erjavec, M. (2012). Validation of food diaries as measures of dietary behaviour change. Appetite, 58, 1164-1168. https://doi.org/10.1016/j.appet.2012.02.017.

Pytte, C. L., \& Fienup, D. M. (2012). Using equivalence-based instruction to increase efficiency in teaching neuroanatomy. Journal of Undergraduate Neuroscience Education, 10, 125-131.

Reyes-Giordano, K., \& Fienup, D. M. (2015). Emergence of topographical responding following equivalencebased neuroanatomy instruction. Psychological Record, 65, 495-507. https://doi.org/10.1007/s40732015-0125-4. 
Rustad Bevolden, K., \& Arntzen, E. (2018). How robust is the correspondence between responding on matching-to-sample tests and sorting tests? Norwegian Journal of Behavior Analysis, 45, 125-142 Retrieved from http://www.nta.atferd.no/journalissue.aspx?IdDocument=729.

Sidman, M., Kirk, B., \& Willson-Morris, M. (1985). Six members stimulus classes generated by conditionaldiscrimination procedures. Journal of the Experimental Analysis of Behavior, 43, 21-42. https://doi. org/10.1901/jeab.1985.43-21.

Sidman, M., \& Tailby, W. (1982). Conditional discrimination vs. matching to sample: an expansion of the testing paradigm. Journal of the Experimental Analysis of Behavior, 37, 5-22. https://doi.org/10.1901 /jeab.1982.37-5.

Stanley, C. R., Belisle, J., \& Dixon, M. R. (2018). Equivalence-based instruction of academic skills: application to adolescents with autism. Journal of Applied Behavior Analysis, 51, 352-359. https://doi. org/10.1002/jaba.446.

Straatmann, G., Almeida, S. S., \& Rose, J. C. (2014). Computerized assessment of food preferences in adolescents in the stimulus equivalence paradigm. Temas em Psicologia, 22, 613-624. https://oi. org/10.9788/tp2014.3-07.

Tay, J., Luscombe-Marsh, N. D., Thompson, C. H., Noakes, M., Buckley, J. D., Wittert, G. A., et al. (2015). Comparison of low- and high-carbohydrate diets for type 2 diabetes management: a randomized trial. The American Journal of Clinical Nutrition, 102, 780-790. https://doi.org/10.3945/ajcn.115.112581.

Tessaro, I., Rye, S., Parker, L., Mangone, C., \& McCrone, S. (2010). Effectiveness of a nutrition intervention with rural low-income women. American Journal of Health Behavior, 31, 35-43.

Varelas, A., \& Fields, L. (2017). Equivalence based instruction by group based clicker training and sorting tests. Psychological Record, 67, 71-80. https://doi.org/10.1007/s40732-016-0208-x.

Vereecken, C., \& Maes, L. (2010). Young children's dietary habits and associations with the mothers' nutritional knowledge and attitudes. Appetite, 54, 44-51. https://doi.org/10.1016/j.appet.2009.09.005.

Walker, B. D., \& Rehfeldt, R. A. (2012). An evaluation of the stimulus equivalence paradigm to teach singlesubject design to distance education students via Blackboard. Journal of Applied Behavior Analysis, 45, 329-344. https://doi.org/10.1901/jaba.2012.45-329.

Walker, B. D., Rehfeldt, R. A., \& Ninness, C. (2010). Using the stimulus equivalence paradigm to teach course material in an undergraduate rehabilitation course. Journal of Applied Behavior Analysis, 43, 615633. https://doi.org/10.1901/jaba.2010.43-615.

Wardle, J., Parmenter, K., \& Waller, J. (2000). Nutrition knowledge and food intake. Appetite, 34, $269-275$. https://doi.org/10.1006/appe.1999.0311.

Yabanc1, N., Kısaç, İ., \& Karakuş, S. Ş. (2014). The effects of mother's nutritional knowledge on attitudes and behaviors of children about nutrition. Procedia - Social and Behavioral Sciences, 116, 4477-4481. https://doi.org/10.1016/j.sbspro.2014.01.970.

Zinn, T. E., Newland, M. C., \& Ritchie, K. E. (2015). The efficiency and efficacy of equivalence-based learning: a randomized controlled trial. Journal of Applied Behavior Analysis, 48, 865-882. https://doi. org/10.1002/jaba.258.

Publisher's Note Springer Nature remains neutral with regard to jurisdictional claims in published maps and institutional affiliations. 